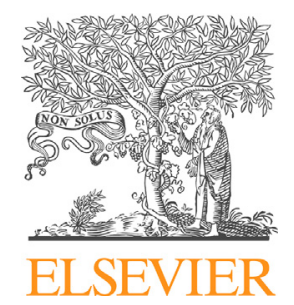

aPenn State College of Medicine, Hershey, PA, 17033, USA

bAlbany Medical Center, Albany, NY 12208, USA

'University of Buffalo, NY, USA

dUniversity Hospital, Gent, Belgium

eUniversity Hospital, UZLeuven, Leuven, Belgium

* Correspondence to: Kanthi Bangalore Krishna, 12 Briarcrest Square, Hershey, PA, 17033, USA. Tel.: +1 717531 4751

kbangalorekrishna@pennstatehealth.psu.edu (K. Bangalore Krishna)

Keywords

Differences of sex development; Complete androgen insensitivity syndrome; Congenital adrenal hyperplasia; Gender assignment; Genital surgery; Vaginoplasty

\section{Abbreviations}

AIS, androgen insensitivity syndrome; $\mathrm{CAH}$, congenital adrenal hyperplasia; DSD,

differences of sex development

Received 1 November 2020 Revised 1 February 2021 Accepted 9 February 2021 Available online $x x x$

Review Article

\title{
Individualized care for patients with intersex (differences of sex development): part 4/5.Considering the Ifs, Whens, and Whats regarding sexual- reproductive system surgery
}

\author{
Kanthi Bangalore Krishna ${ }^{a, *}$, Barry A. Kogan ${ }^{\text {b }}$, Tom Mazur ${ }^{\text {, }}$, \\ Piet Hoebeke ${ }^{d}$, Guy Bogaert ${ }^{e}$, Peter A. Lee ${ }^{a}$
}

\section{Summary}

Issues and concerns regarding surgery of the sexualreproductive anatomy during infancy and early childhood are discussed using four actual examples. A case of a 46, XX infant with 21 hydroxylase deficiency congenital adrenal hyperplasia (CAH) with atypical (ambiguous) genitalia is discussed regarding timing and potential harms and benefits of surgery. We present the perspective of balancing the child's rights to bodily autonomy and right to an open future versus parents' decision making authority regarding what they perceive as their child's future best interests. The second case is a newborn with complete androgen insensitivity syndrome and we

\section{Introduction}

The healthcare of individuals with differences of sex development (DSD) is complex and determined by patient, family, social and legal considerations, particularly the need for full disclosure and patient/family participation in management decisions [1]. There is evidence that approaches to surgical interventions have been shifting, especially avoiding clitoral surgery for those with mild to moderate enlargement [2], with the best example being the type and timing of female genitoplasty. Furthermore, it is apparent that the approach differs among countries based on cultural values, medical policy, resources, openness, and peer-group support [3-6]. This is the 4th part of this series of articles [7-9], reviewing discuss the harms, benefits and timing of gonadectomy. The third case examines the physical and psychological impact of penile shaft hypospadias, raising the question of whether surgery is justified to prevent what may or may not be considered a permanent disability. The fourth case involves an adult woman with classic $\mathrm{CAH}$, born with a urogenital sinus and clitoromegaly, who never had genital surgery and is now requesting vaginoplasty, but not clitoral reduction. The primary message of this article, as the previous articles in this series, is to encourage patient-family centered care that individualizes treatment guided by shared decision making.

care of individuals with DSD. In this article, we review and discuss specific clinical scenarios that highlight the surgical complexities in DSD management and illustrate the need for individualizing decisions regarding surgery for each patient rather than simply applying an algorithm for a given diagnosis. This is not intended to be a research article but the use of specific cases to provide a perspective regarding the care of patients with an emphasis upon individualizing care considering each individuals specific characteristics rather than applying an algorithm based upon diagnosis because of the variation of findings within a specific genetic diagnosis and also each person's personality, temperament and environment. 
1. 46, XX assigned female at birth with diagnosis of Congenital Adrenal Hyperplasia (CAH).

Healthy newborn with genital ambiguity described as Prader $3(2.5 \mathrm{~cm}$ phallus with glans, rugated labioscrotal folds, urogenital sinus orifice between the 'hemiscrotal' folds, no palpable gonads, with uterus and ovaries visualized on ultrasonography) with a 46, XX karyotype. After hormonal and genetic studies verified 21-hydroxylase deficiency CAH, hydrocortisone and fludrocortisone therapy was begun.

Shared decision making including Gender Assignment
After several sessions, during which information was shared
and counseling provided, parents and health care team
agreed upon a female gender assignment. Goal of
assignment was consistent with a reasonable expectation of
stable gender identity development based on current
outcome data ( 88\%) [10]. This is consistent with published
recommendations [11] and is based on the traditional
hypothesis that with consistent adrenal androgen
suppression, nearly all have a good potential for a female
gender identity, positive social and sexual interactions,
good quality of life and fertility potential.
Explanations included pathophysiology of enzyme deficiency
resulting in elevated androgens from the first trimester
throughout life and a review of the embryology of female
and male reproductive tracts as an explanation of their
infant's anatomic genitalia development.
The risks of hyperandrogenism and failure to develop or
maintain a female gender identity were discussed with the
perspective that same-sex orientation or "gender atypical"
behavior should not be considered as an error in gender
assignment.
Options in the timing and extent of surgery were discussed and
that psychosexual differentiation (i.e. gender identity,
innate and volitional gender roles and sexual orientation)
cannot be predicted by sex chromosomes, gonads or genital
anatomy. It was carefully noted that influence of having
atypical genitalia or surgically refashioned genitalia upon
gender identity development is unknown. Alternatives to
surgery involving psychosocial support were discussed
[1,12].

KEY POINTS: This case plus cases with similar physical findings emphasize the need for individualized assessment and counseling of the family based on available outcome data for those with varying extent of virilization. Underlying this is the emphasis on the importance of adherence to hormone replacement therapy (even though this continues to fail to be physiologic). It continues to be the right and responsibility of parents to choose surgery during infancy or delay surgery to allow for patient to be involved in the decision-making process. Parents should be informed of the potential and verified risks, harm and benefits of surgery in relation to timing, emphasizing that decision making during infancy is without the child's participation. Potential benefits of performing early surgery include faster healing, with involvement of more flexible tissues. This allows reconfiguration using tissues that are much closer together than if such surgery occurs at an old age with better vascularization. Early surgery may reeduce the anxiety of parents and children regarding the appearance of their external genitalia. Detractors of early surgery base their approach on the concern that there is insufficient evidence that early surgery benefits gender identity, potential impairment in clitoral sensitivity and high rates of revision for vaginoplasties [13]. That there is no detail regarding a "proper non-surgical pathway" implies that there is a verified care plan for infants born with genital ambiguity. While we agree that most individuals with mild to moderate clitoroplasty should have surgery deferred, it certainly is not clear that deferring surgery for those who will someday require vaginoplasty for sexual activity is the preferred care plan. Further, while it is stated that there is no medical indication, there may well be a psychological indication since growing up with genitalia that are considered to fit gender is likely to impact gender identity. An increased risk of anorgasmia is based upon the surgery done previously and there is evidence that with more refined surgery, the sexual responsiveness has been reported to be similar to control populations [14]. If gender identity ultimately is male and early surgery was performed, parents must be open to adjusting to the consequences. It cannot be overemphasized that the psychological and sexual impact of growing up with non-binary genitalia is unknown but unlikely to be negligible and there are no long-term outcome data comparing those who did and did not have surgery during early life. 


\section{Complete androgen insensitivity syndrome: gonadectomy?}

A healthy newborn presenting with typical female genitalia except bilateral masses palpated within the labia majora. Family history included several members with known complete androgen insensitivity syndrome (CAIS). Mother already assumed this diagnosis for her daughter and expressed awareness of life-long implications. LH and Testosterone levels were elevated and molecular genetic test (AR gene mutation at position c.2495G >A; p.Arg832GI also known as p.Arg830Gln and p.Arg831Gln in the literature) was consistent with this diagnosis.

\begin{tabular}{|c|c|}
\hline Shared decision making including Gender Assignment & Surgery \\
\hline $\begin{array}{l}\text { Female gender was already assigned in this instance by mother. } \\
\text { The natural history and available outcome data were } \\
\text { carefully reviewed. Gender identity and gender role are } \\
\text { known to be virtually universally female; reports of other } \\
\text { aspects of mental health vary in relation to control } \\
\text { populations but were not controlled for age and testes } \\
\text { removal [15,16]. } \\
\text { More than } 1000 \text { AIS-causing variants of the Androgen Receptor } \\
\text { (AR) gene have been described, an ever- broadening } \\
\text { spectrum, making AR gene sequencing useful if known } \\
\text { mutation not found [17]. A positive finding confirms } \\
\text { diagnosis, while a negative result does not exclude it; a } \\
\text { positive family history in an infant with typical physical } \\
\text { findings is suggestive of this diagnosis [18]. A } 2003 \text { report } \\
\text { indicated that about } 90 \% \text { of adults have sexual difficulties, } \\
\text { including infrequency of intercourse and difficulty achieving } \\
\text { vaginal penetration [19]. Parents need to be informed that, } \\
\text { based on outcome data, female identity is very rarely }\end{array}$ & $\begin{array}{l}\text { Biopsy for diagnosis is unnecessary since confirmed by } \\
\text { genetic and/or endocrine findings (elevated LH and } \\
\text { testosterone during infancy). } \\
\text { There continues to be no consensus among surgeons } \\
\text { regarding gonadectomy, risks or age thereof [21], while } \\
\text { the results of an international survey found that } \\
\text { gonadectomy after puberty has been broadly } \\
\text { recommended [22]. Ongoing dialog is recommended } \\
\text { about whether/when to remove gonads. Tumor risk is } \\
\text { minimal until adulthood, and thereafter risk of } \\
\text { malignancy remains low. } \\
\text { Vaginal dilatation should be avoided before puberty } \\
\text { while after estrogen exposure and penetrative } \\
\text { intercourse, it is unnecessary. The adolescent patient } \\
\text { should be involved in the decision regarding vaginal } \\
\text { dilation (assuming they are not sexually active which } \\
\text { should preclude this). The need for psychological } \\
\text { counseling should be periodically assessed. }\end{array}$ \\
\hline
\end{tabular}
challenged by individuals [20]. Focus of counseling should be toward age appropriate full disclosure and psychological adaption of a lifelong condition and consequences including other options of parenthood. Because of the focus upon sex chromosomes, it should be clarified that there are individuals with several diagnoses that are female who have 46, XY karyotypes. The risk of gonadal tumor for age should be part of counseling initially with parents, and later with individual if gonads have not been removed.

KEY POINTS: This case emphasizes the need for individualized assessment and counseling based on available outcome data. Such should begin with comprehensive education about the condition. Previously adult individuals with CAIS indicated dissatisfaction with their care, primarily the assumption of the clear recommendation of a female sex of rearing. Because good adjustment was assumed, it was also assumed that minimal counseling was needed. Complaints included inadequate counseling regarding being a female with a $\mathrm{Y}$ chromosome, fertility/parenthood and potential for sexual function. These also involved the general assumption that surgery to remove gonads should be done during childhood or at least right after puberty, and vaginal dilatation prescribed during childhood and vaginal lengthening procedures before sexual experience. Currently attempts by health caregivers and patient support groups have been to provide education to parents and to patients in an age-appropriate manner. Exogenous estrogen therapy is needed at puberty if gonads have been removed. Annual assessment of endogenous estrogen secretion and some monitoring is recommended after the age of puberty as long as gonads are retained (currently the best recommendation is annual ultrasonography but it is not clear-cut that this approach is beneficial). It also should be noted that there are limited data from trials with androgen therapy [23].

\section{Discussion}

Good long-term outcome should be considered to be based on quality of life including physical, psychological/mental and spiritual or religious facets. Adjustment to having a DSD involves on-going significant risk, life-long observation and, similar to the general population, the possibility that a percentage of these persons will have a poor quality of life because of a host of reasons. Earlier publications in this series addressed the psychosocial and psychosexual aspects in the management of DSD [7,9]. Related to these aspects and surgical choices is a report that suggests an impact of one's perception of their genitalia: a significant association between genital self-image, genital self-consciousness and better "sexual esteem" resulted in greater self-perceived sexual attractiveness [33]. It must be recognized that the role of having binary vs. non-binary genitalia during childhood upon positive adjustment is unclear. 
3. Male born with hypospadias proximal to corona: therapeutic, psychologic or cosmetic? ${ }^{1}$

A one month old baby was seen with a history of distal shaft hypospadias and mild, primarily skin, chordee (see Fig. 1). The baby was otherwise healthy and was being raised as a boy. The pregnancy had been unremarkable and the mother had received no hormones during the pregnancy. The father also had a history of distal hypospadias that has never been repaired. The penis was $4.0 \mathrm{~cm}$ in length and the glans width was $1.3 \mathrm{~cm}$. The baby's testes were descended and normal to palpation.

\begin{tabular}{|c|c|}
\hline Shared decision making including Gender Assignment & Surgery \\
\hline $\begin{array}{l}\text { This boy had already been assigned and raised male and gender } \\
\text { assignment is uniformly male in these cases. Gender } \\
\text { identity is only rarely challenged in distal shaft hypospadias } \\
\text { patients and likely the rate of dysphoria is no different than } \\
\text { the general population. Chromosomal testing is not } \\
\text { indicated in these cases. }\end{array}$ & $\begin{array}{l}\text { Parents should be informed that surgical correction is } \\
\text { optional although surgeons cannot determine whether } \\
\text { the underlying tissues are sufficient to provide for } \\
\text { functional repair. Issues that may occur if no surgery is } \\
\text { performed include spraying of the urinary stream and } \\
\text { chordee interfering with sexual function later in life. }\end{array}$ \\
\hline $\begin{array}{l}\text { Male assignment is challenged when there are concomitant } \\
\text { potentially related abnormalities that might indicate a DSD } \\
\text { (e.g. undescended testes). In those instances, assignment } \\
\text { consideration should be as individualized for the DSD } \\
\text { diagnosis and extreme caution used if a female assignment } \\
\text { is considered. Assignment other than male should not be } \\
\text { considered for those with isolated distal or mid-shaft } \\
\text { location hypospadias. }\end{array}$ & $\begin{array}{l}\text { Many families are concerned with atypical appearance } \\
\text { as well, particularly the dorsal hooded foreskin. It is } \\
\text { possible to wait until the child is old enough to } \\
\text { participate in the decision making, however counseling } \\
\text { should include that success rates in infancy are likely } \\
90+\% \text { and many more complications are noted in older } \\
\text { patients operated on for hypospadias. Many parents also } \\
\text { wish to spare their child what they perceive as potential }\end{array}$ \\
\hline $\begin{array}{l}\text { The parents should be informed that there is every likelihood } \\
\text { of their son leading a normal life in all respects. Outcomes } \\
\text { studies of patients with distal hypospadias have been } \\
\text { uniformly positive, especially when penile size is normal. } \\
\text { This is in contrast to proximal hypospadias where recurrent }\end{array}$ & $\begin{array}{l}\text { embarrassment of the uncorrected atypical appearance. } \\
\text { In patients who choose not to proceed with surgery, } \\
\text { many parents perceive a higher rate of UTIs or infertility } \\
\text { but they should be reassured that there are no data to } \\
\text { support those concerns. }\end{array}$ \\
\hline
\end{tabular}
chordee and small penile size is associated with more difficulties. However, it should be noted that some parents of young boys and older affected individuals have expressed regret because of surgical complications [24,25]which may occur with this complicated surgery (not long-term results). It is noted that the outcome study in adult males suggests that deferring repair until the patient can decide is not warranted.

The parents should understand that boys with mild or moderate hypospadias can expect normal testicular function including spermatogenesis and that the principal decision relates to need for and timing of surgery. The importance of the appearance of the penis at development stages should be discussed [26-28]. If the physical and psychological aspects involve not being able to stand to urinate without wetting clothing and mis-directed ejaculate delivery during sexual activity, surgery should be considered even though the urethral opening without repair functions as the outlet for urine and after puberty, for semen.

Significant associated chordee may affect sexual function. On-going counseling should be available and need thereof periodically assessed.

Key Points: Clinicians realize that the impact of the urethral opening on the ventral side of the penis may preclude standing to urinate because lack of a directed stream and resultant wetting of clothing. Psychologists do not agree on the psychological impact of growing up being unable to stand to urinate or urinate standing beside other males. To be fair to those with hypospadias, criteria for considering surgery needs to involve not only physical harm, but also psychological impact. In this case the father had hypospadias himself and understood that urinary and sexual function (and fertility) would be acceptable. Although he indicated satisfactory sexual intercourse and was "happily" married, he felt he had been different his whole life and he asked specifically that his son be repaired.

${ }^{1}$ It is acknowledged that distal hypospadias without other genital findings may or may not be considered a DSD. 
4. 46, XX female with CAH, atypical (ambiguous) genitalia with urogenital sinus and clitoromegaly, presenting in adulthood, requesting vaginoplasty but not clitoral reduction.

A 19 year old female who was born with genital ambiguity (Prader 3) was diagnosed with CAH and prescribed glucocorticoid and mineralocorticoid therapy to suppress adrenal androgen excess from birth onwards. She has been very adherent with therapy during childhood and adolescence. She had minimal cosmetic surgery (partial resection of clitoral hood) early in life without vaginoplasty or clitoral reduction. There is a vaginal opening sufficient to accommodate menstrual flow. Psychosocial development was healthy and sexual orientation is bisexual. She has had non-penetrative sexual experiences and now requests vaginoplasty without clitoral reduction.

\begin{tabular}{ll}
\hline Shared decision making & Surgery \\
\hline This 46, XX individual with CAH has a clear female gender & This patient has no concerns regarding the size of her clitoris
\end{tabular}

is 46, XX individual with CAH has a clear female gender This patient has no concerns regarding the size of her clitoris identity typical for most with CAH and Prader 3 (see case 1). which measures $6 \mathrm{~cm}$ when erect and she considers this It is pertinent that this developed despite growing up with advantageous for sexual experience. Vaginoplasty without virilized genitalia (no clitoral reduction or vaginal surgery). clitoral surgery was performed and after a dilation program,

While this individual appears well adjusted, she was not cared the patient had a vagina accessible for intercourse. She was for by a multidisciplinary team including a behavioral health pleased with the result.

provider. She did not have formal counseling.

At the age of 19 , she was able to choose reconstructive surgery

It was considered important to reassure her, consistent with based on her sexual experience. In this case, not performing the goal of individualized care, that whatever she has decided or will decide regarding surgery and her sexual early reconstructive surgery had no obvious negative effect on behavior is her personal privilege and decision. this patient's psychosocial and sexual development. This family and patient's conscious choice deviated from the previous surgical recommendations that reconstruction should be performed early. However, delaying clitoral surgery in patients with Prader 3 virilization is more common currently, given the fear of reduced sensitivity related to clitoral reduction $[14,29,30]$.

KEY POINTS: This case illustrates a significant conundrum regarding feminizing surgery in significantly virilized $46, X X$ patients. There is a feasibility study regarding deferring surgery among adolescent girls [31]. Such cases form the basis of advocates' arguments against early surgery even though outcome data with this approach are extremely limited. This case emphasizes the need for individualized assessment and counseling of individuals, and for minors and the family. Current counseling must be based on available, albeit limited outcome data. Given limited data and inclusion of patients with varying amounts of virilization, older surgical techniques and undocumented counseling, predication of outcomes is not currently feasible. During infancy and early childhood, it is the parents' right and responsibility to choose or delay surgery. The clear advantage of postponing surgery is that it allows the patient to be involved in the decision making process even though: 1) the age at which the patient can make that decision varies, is unclear and must be individualized after careful psychological assessment and 2) the psychological impact of growing up with non-binary genitalia remains uncertain. Although not necessarily generalizable, this case illustrates that a healthy psychological outcome is possible (at least through early adulthood) without feminizing clitoral surgery. There is insufficient evidence that early surgery benefits gender identity, potential impairment in clitoral sensitivity and high rates of revision for vaginoplasties. The risk of anorgasmia is based upon the surgery done previously and there is evidence that with more refined surgery sexual responsiveness has been reported to be similar to control populations [32]. Further, if gender dysphoria develops, this approach allows for the option of phalloplasty from local tissue.

Considerations about surgery of the reproductive system will continue to be contentious for the foreseeable future. Broad, long-term controlled studies involving comparison groups are needed. In the meantime, parents of children having DSDs with different etiologic diagnoses continue to exercise their rights and make decisions on behalf of their minor children. A recent publication [1] suggests constructive paths forward include shared decision-making resulting in individualized recommendations via comprehensive, integrated care teams which incorporate mental health services. The intent of surgical management of genital and gonadal surgery has and continues to benefit the patient not only physically but also psychosexually and psychosocially. Indeed, parents who chose surgery indicate that their desire was to enhance their child's psychosocial and psychosexual adaption. The decisions regarding genital surgery for a child with DSD may be the most difficult parents will ever make and this is why the process of shared decision-making is so important. This is also why multidisciplinary team members need to be aware of the factors that may predict anguish among parents of those with DSD. To evaluate factors that may predict such distress among parents of children with DSD [33], themes for decision making regarding surgery among those with DSD and individual considerations based upon genetic, physiologic and psychologic assessments have been published [34]. 


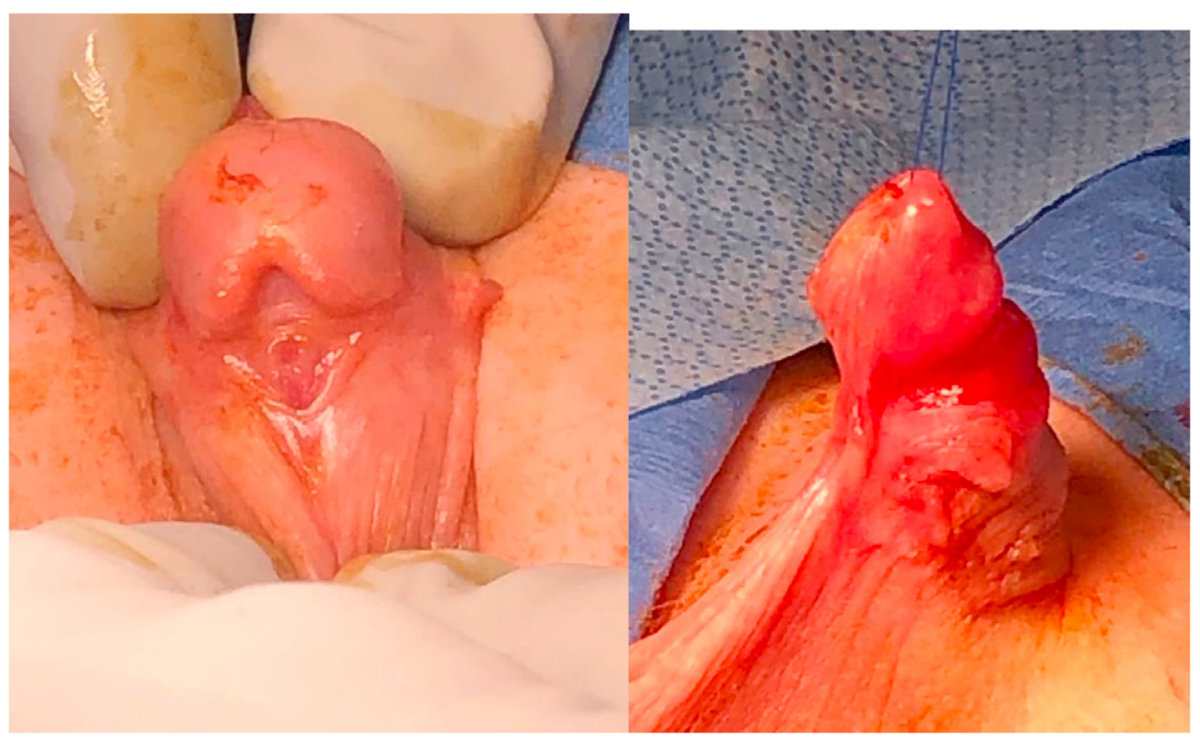

Fig. 1 Distal shaft hypospadias and mild, primarily skin, chordee.

Regarding the cases presented in the report, the question of early surgery for infants with 21 hydroxylase deficiency CAH and a 46,XX karyotype with significant atypical (ambiguous) genitalia continues to be without sufficient long-term (adult) outcome data. The most recent clinical practice guidelines for 21-hydroxylase deficiency $\mathrm{CAH}$ do not address the surgical controversy or include recommendations regarding surgery [11]. A systemic review and meta-analysis of genital reconstructive surgery from 2018 [10] included 29 observational studies (1178 patients, mostly classic with mean age at surgery, $2.7 \pm 4.7$ years). After an average follow-up of 10.3 years, a larger portion than previously reported $(11.3 \%)$ did not have a female gender identity and were not heterosexual (23.8\%). Most patients were sexually active and satisfied with the surgical outcomes; others complained of impaired sexual experience and satisfaction. Data on quality of life were sparse and inconclusive and the authors state that the certainty in the available evidence is very low. A cross-sectional cohort analysis illustrates the multiple factors involved in sexual function outcomes by including those who had normal genitalia (non-classical individuals). This group plus others with clinical signs of hyperandrogenism had higher distress regarding sexual function compared to women without clinical signs of hyperandrogenism, highlighting the importance of early diagnosis and therapy initiation in all patients with $\mathrm{CAH}$ including those with non-classical $\mathrm{CAH}$ $[35,36]$. How efficacious surgical external genital construction is in overall good quality of life depends not only the quality of surgery but other factors, some of which are alluded to above.

Clinical presentations and management of complete androgen insensitivity syndrome (CAIS) has been recently extensively reviewed [37]. It is clear that the risk of germ cell tumors is lower than among some other DSD diagnoses at $<1 \%$ but may be greater than $20 \%$ among adults. To date, no association has been found for one or more known single nucleotide polymorphism and pre-germ cell neoplasia in situ, germ cell neoplasia in situ or invasive cancer [38]. The case of complete androgen insensitivity syndrome presented above provides a basis for discussing when and if gonadectomy should be done among those with AIS and other DSD diagnoses. Based on current epidemiologic outcome studies, gonadectomy can be postponed until after the age of puberty allowing for spontaneous feminizing puberty and postponement of need for hormonal replacement therapy [39]. From puberty onward, the question should be periodically revisited including gonadal ultrasound studies screening for evidence of testicular germ cell tumors and the decision made whether the malignancy risk is such that the gonads should be removed [40]. Guides to assessing gonadal germ cell tumor predisposition among those with AIS, other DSD diagnoses as well as non-DSD syndrome and a review article of histological assessment of gonads in DSD were published in 2017 [41,42].

The questions regarding surgery for hypospadias is particularly complex since the urethral opening may be located slightly below the tip of the penis to the base of the penis on the perineum and the development of underlying tissue cannot be determined until surgical exploration [43]. Hypospadias located along the ventral side of the shaft (mid-shaft) is usually considered for surgery. General considerations for surgery were summarized in 2008 and state that the best approach for good outcomes involve microsurgery, fine suture materials, appropriate planning for one or two-stage repair, at ages between 6 and 18 months and good postoperative care [44]. Except for instances of significant complications of surgery, both the patient and parents retrospectively have been pleased to have had surgery during infancy. While complications of hypospadias surgery must be part of full disclosure, this should not be an overriding reason to decide against surgery [45]. Parents must realize that much that has been written in print or on line is opinion without verified outcome data, often based upon a few instances of poor outcome presented in a dramatic fashion. It is clear that how the question is framed to parents by presenters influence choice and whether the anatomic problem is considered beyond a variation of 
normal. A systematic review of publications that documented psychosocial risk factors among boys with hypospadias including quality of life, psychosocial and psychosexual adjustments [46], considering the severity of hypospadias, verifies that boys with hypospadias "suffer from negative genital appraisal and sexual inhibitions". A recent publication [47] suggests that health care professionals talk about hypospadias surgery with an approach that supports parents making decisions for hypospadias surgery, while psychologists frame such in such a way to enable a non-medical pathway focusing on psychological qualities such as "affect, well-being and unconditional positive regard". The suggested psychological pathway would "frame" for parents their son's penile difference in terms of well-being and suggest that there need not be negative psychosocial effects, minimizing the importance of being able to stand to urinate, to urinate without getting clothing wet, in addition to having a penis which is incompletely formed which may cause both physical and psychological sexual problems in the future. In deciding regarding hypospadias surgery, individualized evaluation of the projected physical, sexual and psychological outcomes must be considered.

The last case of a 46, XX female with $\mathrm{CAH}$ who has had no prior genital surgery is a most enlightening, although isolated case, concerning consideration of reduction clitoroplasty at any age. Details of her medical treatment are not available, although she has a normal menstrual history without heavy bleeding. She has atypical (ambiguous) genitalia with urogenital sinus and clitoromegaly. She sought surgical consultation accompanied by a girlfriend requesting vaginoplasty but not clitoral reduction. She expresses no concern about the size of her clitoris and this adult outcome is very important for consideration of clitoroplasty at any age [48,49]. Importantly, the preservation of clitoral sensitivity is not a risk in contrast to early surgery as seen in case 1 [30].

Throughout this report, we have attempted to cite literature that adds to the focus of this article, however the limitation is the result of the lack of good quality long-term outcome studies, a problem that has existed for decades. This problem relates to the difficulties/impossibilities of designing such trials, the rarity of some conditions, the heterogeneity within a single diagnostic population, and the changing care, especially including refined surgical techniques that impact outcome.

In conclusion, this report attempts to review the surgical conundrums in children with DSDs and suggests a balanced view to approach these patients. Instead of applying a rote algorithmic approach for each category, we suggest an individualized approach with a multi-disciplinary team practicing shared decision making considering currently available outcome data.

\section{Funding}

None.

\section{Conflict of interest}

\section{References}

[1] Gardner M, Sandberg DE. Navigating surgical decision making in disorders of sex development (DSD). Front Pediatr 2018;6: 339.

[2] Lee PA, Witchel SF. Genital surgery among females with congenital adrenal hyperplasia: changes over the past five decades. J Pediatr Endocrinol Metab 2002;15(9):1473-7.

[3] Danon LM. Comparing contemporary medical treatment practices aimed at intersex/DSD bodies in Israel and Germany. Sociol Health Illness 2019;41(1):143-64.

[4] Wiesemann C, Ude-Koeller S, Sinnecker GH, Thyen U. Ethical principles and recommendations for the medical management of differences of sex development (DSD)/intersex in children and adolescents. Eur J Pediatr 2010;169(6):671-9.

[5] Baratz AB, Sharp MK, Sandberg DE. Disorders of sex development peer support. Endocr Dev 2014;27:99-112.

[6] Hiort O, Ahmed SF. Understanding differences and disorders of sex development. Foreword. Endocr Dev 2014;27:VII-VIII.

[7] Bangalore Krishna K, Kogan BA, Ernst MM, Romao RL, Mohsin F, Serrano-Gonzalez $M$, et al. Individualized care for patients with intersex (disorders/differences of sex development): Part 3. J Pediatr Urol 2020 Oct;16(5):598-605. https: //doi.org/10.1016/j.jpurol.2020.06.004.

[8] Lee PA, Fuqua JS, Houk CP, Kogan BA, Mazur T, Caldamone A. Individualized care for patients with intersex (disorders/differences of sex development): part I. J Pediatr Urol 2020 Apr;16(2):230-7.

//doi.org/10.1016/j.jpurol.2020.02.013.

[9] Ernst MM, Kogan BA, Lee PA. Gender identity: a psychosocial primer for providing care to patients with a disorder/difference of sex development and their families [individualized care for patients with intersex (Disorders/differences of sex development): Part 2]. J Pediatr Urol 2020. https: //doi.org/10.1016/j.jpurol.2020.06.026.

[10] Almasri J, Zaiem F, Rodriguez-Gutierrez R, Tamhane SU, Iqbal AM, Prokop LJ, et al. Genital reconstructive surgery in females with congenital adrenal hyperplasia: a systematic review and meta-analysis. J Clin Endocrinol Metab 2018; 103(11):4089-96.

[11] Speiser PW, Arlt W, Auchus RJ, Baskin LS, Conway GS, Merke DP, et al. Congenital adrenal hyperplasia due to steroid 21-hydroxylase deficiency: an endocrine society clinical practice guideline. J Clin Endocrinol Metab 2018;103(11): 4043-88.

[12] Liao LM, Wood D, Creighton SM. Parental choice on normalising cosmetic genital surgery. BMJ 2015;351:h5124.

[13] Yankovic F, Cherian A, Steven L, Mathur A, Cuckow P. Current practice in feminizing surgery for congenital adrenal hyperplasia; a specialist survey. J Pediatr Urol 2013;9(6 Pt B): 1103-7.

[14] Nordenström A, Frisén L, Falhammar $H$, Filipsson $H$, Holmdahl G, Janson PO, et al. Sexual function and surgical outcome in women with congenital adrenal hyperplasia due to CYP21A2 deficiency: clinical perspective and the patients' perception. J Clin Endocrinol Metab 2010;95(8):3633-40.

[15] Jürgensen M, Hiort O, Holterhus PM, Thyen U. Gender role behavior in children with $\mathrm{XY}$ karyotype and disorders of sex development. Horm Behav 2007;51(3):443-53.

[16] Hines M, Ahmed SF, Hughes IA. Psychological outcomes and gender-related development in complete androgen insensitivity syndrome. Arch Sex Behav 2003;32(2):93-101.

[17] Hughes IA, Werner R, Bunch T, Hiort O. Androgen insensitivity syndrome. Semin Reprod Med 2012;30(5):432-42.

[18] Yuan SM, Zhang YN, Du J, Li W, Tu CF, Meng LL, et al. Phenotypic and molecular characteristics of androgen

None. 
insensitivity syndrome patients. Asian J Androl 2018;20(5): 473-8.

[19] Minto CL, Liao KL, Conway GS, Creighton SM. Sexual function in women with complete androgen insensitivity syndrome. Fertil Steril 2003;80(1):157-64.

[20] Wisniewski AB, Mazur T. 46,XY DSD with female or ambiguous external genitalia at birth due to androgen insensitivity syndrome, 5alpha-reductase-2 deficiency, or 17beta-hydroxysteroid dehydrogenase deficiency: a review of quality of life outcomes. Int J Pediatr Endocrinol 2009;2009:567430.

[21] Lee PA, Nordenström A, Houk CP, Ahmed SF, Auchus R, Baratz A, et al. Global disorders of sex development update since 2006: perceptions, approach and care. Horm Res Paediatr 2016;85(3):158-80.

[22] Tack LJW, Maris E, Looijenga LHJ, Hannema SE, Audi L, Köhler B, et al. Management of gonads in adults with androgen insensitivity: an international survey. Horm Res Paediatr 2018; 90(4):236-46.

[23] Birnbaum W, Marshall L, Werner R, Kulle A, Holterhus PM, Rall K, et al. Oestrogen versus androgen in hormonereplacement therapy for complete androgen insensitivity syndrome: a multicentre, randomised, double-dummy, double-blind crossover trial. Lancet Diabetes Endocrinol 2018; 6(10):771-80.

[24] Lorenzo AJ, Pippi Salle JL, Zlateska B, Koyle MA, Bägli DJ, Braga LH. Decisional regret after distal hypospadias repair: single institution prospective analysis of factors associated with subsequent parental remorse or distress. J Urol 2014; 191(5 Suppl):1558-63.

[25] Tack LJW, Springer A, Riedl S, Tonnhofer U, Weninger J, Hiess $M$, et al. Psychosexual outcome, sexual function, and long-term satisfaction of adolescent and young adult men after childhood hypospadias repair. J Sex Med 2020 Sep;17(9): 1665-75. https://doi.org/10.1016/j.jsxm.2020.04.002.

[26] Weber DM, Schönbucher VB, Landolt MA, Gobet R. The Pediatric Penile Perception Score: an instrument for patient selfassessment and surgeon evaluation after hypospadias repair. J Urol 2008;180(3):1080-4. discussion 1084.

[27] Weber DM, Landolt MA, Gobet R, Kalisch M, Greeff NK. The Penile Perception Score: an instrument enabling evaluation by surgeons and patient self-assessment after hypospadias repair. J Urol 2013;189(1):189-93.

[28] Daae E, Feragen KB, Nermoen I, Falhammar H. Psychological adjustment, quality of life, and self-perceptions of reproductive health in males with congenital adrenal hyperplasia: a systematic review. Endocrine 2018;62(1):3-13.

[29] Nordenström A. Adult women with 21-hydroxylase deficient congenital adrenal hyperplasia, surgical and psychological aspects. Curr Opin Pediatr 2011;23(4):436-42.

[30] Crouch NS, Liao LM, Woodhouse CR, Conway GS, Creighton SM. Sexual function and genital sensitivity following feminizing genitoplasty for congenital adrenal hyperplasia. J Urol 2008; $179(2): 634-8$.

[31] Bougnères $P$, Bouvattier $C$, Cartigny $M$, Michala L. Deferring surgical treatment of ambiguous genitalia into adolescence in girls with 21-hydroxylase deficiency: a feasibility study. Int J Pediatr Endocrinol 2017;2017:3.

[32] Lesma A, Bocciardi A, Corti S, Chiumello G, Rigatti P, Montorsi F. Sexual function in adult life following PasseriniGlazel feminizing genitoplasty in patients with congenital adrenal hyperplasia. J Urol 2014;191(1):206-11.

[33] Amos N, McCabe M. Positive perceptions of genital appearance and feeling sexually attractive: is it a matter of sexual esteem? Arch Sex Behav 2016;45(5):1249-58.
[34] Perez MN, Delozier AM, Aston CE, Austin P, Baskin L, Chan YM, et al. Predictors of psychosocial distress in parents of young children with disorders of sex development. J Urol 2019; 202(5):1046-51.

[35] Crawford JM, Warne G, Grover S, Southwell BR, Hutson JM. Results from a pediatric surgical centre justify early intervention in disorders of sex development. J Pediatr Surg 2009; 44(2):413-6.

[36] Schernthaner-Reiter MH, Baumgartner-Parzer S, Egarter HC, Krebs M, Kautzky-Willer A, Kirchheiner K, et al. Influence of genotype and hyperandrogenism on sexual function in women with congenital adrenal hyperplasia. J Sex Med 2019;16(10): 1529-40.

[37] Lanciotti L, Cofini M, Leonardi A, Bertozzi M, Penta L, Esposito S. Different clinical presentations and management in complete androgen insensitivity syndrome (CAIS). Int J Environ Res Publ Health 2019;16(7).

[38] Cools M, Wolffenbuttel KP, Hersmus R, Mendonca BB, Kaprová J, Drop SLS, et al. Malignant testicular germ cell tumors in postpubertal individuals with androgen insensitivity: prevalence, pathology and relevance of single nucleotide polymorphism-based susceptibility profiling. Hum Reprod 2017;32(12):2561-73.

[39] de Fine Licht S, Winther JF, Gudmundsdottir T, Holmqvist AS, Bonnesen TG, Asdahl PH, et al. Hospital contacts for endocrine disorders in Adult Life after Childhood Cancer in Scandinavia (ALiCCS): a population-based cohort study. Lancet 2014;383(9933):1981-9.

[40] Cools M, Looijenga L. Update on the pathophysiology and risk factors for the development of malignant testicular germ cell tumors in complete androgen insensitivity syndrome. Sex Dev 2017;11(4):175-81.

[41] Spoor JA, Oosterhuis JW, Hersmus R, Biermann K, Wolffenbuttel KP, Cools M, et al. Histological assessment of gonads in DSD: relevance for clinical management. Sex Dev 2018;12(1-3):106-22.

[42] Pyle LC, Nathanson KL. A practical guide for evaluating gonadal germ cell tumor predisposition in differences of sex development. Am J Med Genet C Semin Med Genet 2017; 175(2):304-14.

[43] Keays MA, Dave S. Current hypospadias management: diagnosis, surgical management, and long-term patientcentred outcomes. Can Urol Assoc J 2017;11(1-2Suppl1): S48-53.

[44] Bhat A. General considerations in hypospadias surgery. Indian J Urol 2008;24(2):188-94.

[45] Myers JB, McAninch JW, Erickson BA, Breyer BN. Treatment of adults with complications from previous hypospadias surgery. J Urol 2012;188(2):459-63.

[46] Schönbucher VB, Weber DM, Landolt MA. Psychosocial adjustment, health-related quality of life, and psychosexual development of boys with hypospadias: a systematic review. J Pediatr Psychol 2008;33(5):520-35.

[47] Roen K, Hegarty P. Shaping parents, shaping penises: how medical teams frame parents' decisions in response to hypospadias. Br J Health Psychol 2018;23(4):967-81.

[48] Wisniewski AB, Tishelman AC. Psychological perspectives to early surgery in the management of disorders/differences of sex development. Curr Opin Pediatr 2019; $31(4): 570-4$.

[49] Binet A, Lardy H, Geslin D, Francois-Fiquet C, Poli-Merol ML. Should we question early feminizing genitoplasty for patients with congenital adrenal hyperplasia and XX karyotype? J Pediatr Surg 2016;51(3):465-8. 